\title{
Work-related musculoskeletal disorders among nurses in various specialty areas in a Nigerian tertiary health institution
}

\author{
Samuel Olufemi Bolarinde*, Isaiah Oyewole, Adesola Felix Abobarin
}

Department of Physiotherapy, Federal Medical Centre, Owo, Nigeria

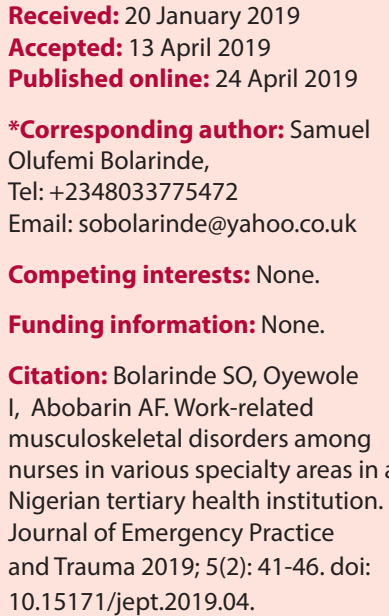

\begin{abstract}
Objective: Musculoskeletal disorders (MSDs) are one of the major complaints in the work place. This study investigated the prevalence and pattern of work-related MSDs, risk factors and the strategies of management among nurses working in various specialty areas in a tertiary health institution in Nigeria.

Methods: This cross-sectional survey recruited 150 nurses working in various specialty areas of a government own tertiary institution in South-west, Nigeria. Data were obtained on demographic characteristics, occupational profile, work-related musculoskeletal symptoms, perceptions on job risk factors and management strategies. Data were presented using descriptive statistics of percentages and frequency tables.

Results: The most common MSD among the respondents was low back pain (LBP) (60.0\%), followed by neck pain $(48.0 \%)$, while elbow pain was the lowest work-related musculoskeletal pain (5.3\%). Findings indicated that respondents working in Intensive Care Unit (100.0\%), Dental Unit (100.0\%), Accident and Emergency (77.8\%), Orthopaedics (75.0\%), Ear Nose and Throat $(75.0 \%)$ and Medicine $(72.7 \%)$ suffered from LBP more than other respondents in other specialty areas. Results also revealed that frequent bending (64.0\%), prolonged standing (49.3\%) and frequent lifting of patients $(48.0 \%)$ were major factors that contributed to LBP among the respondents. Rest (56.0\%), pain killer drugs (50.7\%), and exercise $(36.0 \%)$ were the most preferred pain management strategies among the respondents, while only $12.0 \%$ preferred physiotherapy management.

Conclusion: A great percentage of Nigerian nurses suffer from work-related MSDs in their professions with the low back being the most injured body part. Nurses working in Intensive Care Unit, Dental, Accident and Emergency and Orthopedics are more prone to work-related LBP. Education programs on back care and workplace ergonomics are recommended for reduction and prevention of occupational hazards among nurses.

Keywords: Nurses, Work-related musculoskeletal disorders, Low back pain, Nigeria
\end{abstract}

\section{Introduction}

Musculoskeletal disorders (MSDs) are painful anatomical defects that are characterized by inflammatory and degenerative conditions in muscles, tendons, ligaments, joints, peripheral nerves, and supporting blood vessels $(1,2)$. MSDs are an important public health challenge and one of the major complaints in work place (3). Work-related MSDs (WMSDs) are defined as MSDs that result from work-related activities (4). WMSDs are common among hospital workers particularly the nursing profession $(5,6)$. These disorders are often characterized by pain and complaint in hand, wrist, elbow, shoulder, neck, low back, foot and legs.

Several epidemiology studies have shown that extrinsic occupational factors (manual handling activities, frequent bending and twisting, forceful movement, repetitive heavy lifting and awkward working posture) (7-9), intrinsic personal factors (age, gender, body mass variability and tobacco smoking) $(10,11)$, and psychological factors (high job demand, low control, low mood and poor job satisfaction) $(12,13)$ are important risk factors for WMSDs.

Previous epidemiological studies have reported that WMSDs negatively affect the quality of life (1), cause loss of productive hours, and increase the level of functional disability (12-14) more than any other group of diseases $(15,16)$ with a significant economic burden on the individual, family, the organization and the society (17).

Nurses among other health workers routinely perform work activities that predispose them to WMSDs. These activities include bed making, patient hygiene, changing patients' position and maintenance of awkward working 
postures (18-20) which put nurses at a high risk for acute and recurrent WMSDs. Previous epidemiological studies have reported the prevalence of musculoskeletal symptoms resulting from tasks that overload the body musculature among nurses $(19,20)$.

Although the prevalence of WMSDs among nurses has been documented in the developed world $(21,22)$, however, data on the pattern of WMSDs among nurses across various specialty areas in Nigeria has not been fully investigated. This study was designed to investigate the prevalence and pattern of WMSDs, risk factors and managing strategies among nurses working in various specialty areas in a Nigerian tertiary health institution.

\section{Methods}

A cross-sectional survey was conducted on the prevalence of work-related MSDs among nurses working in various specialty areas of Federal Medical Centre, Owo, Nigeria. The rationale behind the study was explained to all participants and informed consent was granted from them before their participation. The survey instrument for the study was a four sectioned questionnaire. Section $\mathrm{A}$ was on demographic profile, while section B was on occupational health in nursing practice and work history such as: years of practice, work setting, practice specialty, and nursing activities. A standardized Nordic questionnaire (23) sought information on the symptom-survey of the occupational health in nursing practice. Section $\mathrm{C}$ sought information on job risk factors and effects of MSDs, while section D consisted of data on management strategies. Data were summarized using Statistical Package for Social Science (SPSS) version 20.0 software. Results were presented in the percentages and frequency tables.

\section{Results}

A total of 150 nurses participated in this study in which $130(86.7 \%)$ were females and only $20(13.3 \%)$ were males. Concerning the marital status, $16(10.7 \%)$ were single, $130(86.7 \%)$ were married and 4 (2.7\%) were widowed. Regarding the age, 31-40 was the age group with the highest percentage (44.0\%) followed by $41-50(40.0 \%)$, while 21-30 age group had the least percentage (6.7\%) (Table 1). In terms of work experience, 16-20 years of working experience had the highest percentage (26.7\%) among the respondents, while 31 years and above was the year of experience with the lowest percentage (1.3\%). Concerning qualification, 114 (76.0\%) had Bachelor of Nursing Science degree as the highest qualification, while $2(1.3 \%)$ had Master of Science degree in nursing. Results also showed that Medical unit had the highest number of nurses (14.7\%) followed by Accident and Emergency unit (12.0\%), while the Intensive Care Unit had the lowest number of nurses $(2.7 \%)$ in the hospital.

Table 2 shows that low back pain (LBP) (60.0\%) was the most common MSD among the respondents followed by neck pain $(48.0 \%)$, while elbow pain was the lowest
Table 1. Socio-demographic characteristics of respondents $(N=150)$

\begin{tabular}{|c|c|c|c|}
\hline & & No. & $\%$ \\
\hline \multirow{4}{*}{ Age group } & $21-30$ & 10 & 6.7 \\
\hline & $31-40$ & 66 & 44.0 \\
\hline & $41-50$ & 60 & 40.0 \\
\hline & $51-60$ & 14 & 9.3 \\
\hline \multirow{2}{*}{ Gender } & Male & 20 & 13.3 \\
\hline & Female & 130 & 86.7 \\
\hline \multirow{3}{*}{ Marital status } & Single & 16 & 10.7 \\
\hline & Married & 130 & 86.7 \\
\hline & Widow & 4 & 2.7 \\
\hline \multirow{7}{*}{$\begin{array}{l}\text { Years of } \\
\text { experience }\end{array}$} & $1-5$ & 12 & 8.0 \\
\hline & $6-10$ & 36 & 24.0 \\
\hline & $11-15$ & 32 & 21.3 \\
\hline & $16-20$ & 40 & 26.7 \\
\hline & $21-25$ & 20 & 13.3 \\
\hline & $26-30$ & 8 & 5.3 \\
\hline & $\geq 31$ & 2 & 1.3 \\
\hline \multirow{3}{*}{ Qualification } & Diploma & 34 & 22.7 \\
\hline & B. NSC & 114 & 76.0 \\
\hline & MSc & 2 & 1.3 \\
\hline \multirow{14}{*}{$\begin{array}{l}\text { Specialty of } \\
\text { work }\end{array}$} & $A \& E$ & 18 & 12.0 \\
\hline & Medicine & 22 & 14.7 \\
\hline & Surgery & 12 & 8.0 \\
\hline & ICU & 4 & 2.7 \\
\hline & O\&G & 16 & 10.7 \\
\hline & Psychiatry & 10 & 6.7 \\
\hline & Paedriatrics & 16 & 10.7 \\
\hline & Children Emergency & 12 & 8.0 \\
\hline & Orthopaedics & 8 & 5.3 \\
\hline & Theatre & 6 & 4.0 \\
\hline & Dental Dept & 6 & 4.0 \\
\hline & Ophthalamology & 6 & 4.0 \\
\hline & ENT & 8 & 5.3 \\
\hline & Community Health & 6 & 4.0 \\
\hline
\end{tabular}

work-related musculoskeletal pain (5.3\%) among the respondents. Findings also showed that $37.3 \%$ of the respondents could not do their normal work due to LBP; similarly, $26.7 \%$ of respondents could not do their normal work due to neck pain, while $20.0 \%$ of the respondents with knee pain could not do their normal work. The results revealed that female respondents (53.33\%) suffered from LBP more than their male counterparts $(6.67 \%)$. Similarly, married participants $(53.33 \%)$ suffered from LBP more than singles (3.99\%) and widowed participants (2.67\%), while the participants in the age range of 41-50 years $(29.33 \%)$ suffered more from LBP compared with participants in other age groups.

Table 3 shows that Intensive Care Unit and Dental unit had the highest percentage of respondents (100\%) that suffered from work-related LBP followed by Accident and Emergency (77.8\%), 75.0\% in Orthopaedics, $75.0 \%$ in Ear Nose and Throat and $72.7 \%$ in Medicine unit. Also, results showed that $100 \%$ of respondents in Intensive Care Unit, $77.8 \%$ in Accident and Emergency unit, $72.7 \%$ in Medicine unit and $75 \%$ in Ear Nose and Throat suffered 
Table 2. Pattern of Work-Related Musculoskeletal Pain Among Respondents

\begin{tabular}{|c|c|c|c|c|c|c|}
\hline \multirow[t]{2}{*}{ Body part } & \multicolumn{2}{|c|}{$\begin{array}{l}\text { Have had pain in the last } 12 \\
\text { months }\end{array}$} & \multicolumn{2}{|c|}{$\begin{array}{l}\text { Have been prevented from doing normal } \\
\text { work because of the pain? In the last } 12 \\
\text { months }\end{array}$} & \multicolumn{2}{|c|}{$\begin{array}{l}\text { Have had pain at any time during } \\
\text { the last } 7 \text { days? }\end{array}$} \\
\hline & No. & $\%$ & No. & $\%$ & No. & $\%$ \\
\hline Neck & 72 & 48.0 & 40 & 26.7 & 20 & 13.33 \\
\hline Shoulder & 46 & 30.7 & 18 & 12.0 & 24 & 16.0 \\
\hline Elbow & 8 & 5.3 & 6 & 4.0 & 0 & 0.0 \\
\hline Wrist/hand & 32 & 21.3 & 22 & 14.7 & 14 & 9.3 \\
\hline Upper back & 44 & 29.3 & 24 & 16.0 & 18 & 12.0 \\
\hline Lower back & 90 & 60.0 & 56 & 37.3 & 28 & 18.7 \\
\hline One or both hips/thigh & 28 & 18.7 & 14 & 9.3 & 12 & 8.0 \\
\hline One or both knees & 50 & 33.3 & 30 & 20.0 & 18 & 12.0 \\
\hline One or both ankles/feet & 14 & 9.3 & 10 & 6.5 & 8 & 5.3 \\
\hline Variables & $\begin{array}{l}\text { Have ha } \\
\text { back in th }\end{array}$ & $\begin{array}{l}\text { the low } \\
\text { months }\end{array}$ & $\begin{array}{r}\text { Have been pre } \\
\text { work becau }\end{array}$ & $\begin{array}{l}\text { oing normal } \\
\text { ack pain? }\end{array}$ & $\begin{array}{l}\text { Have had } \\
\text { the last } 7\end{array}$ & $\begin{array}{l}\text { time during } \\
\text { low back? }\end{array}$ \\
\hline \multicolumn{7}{|l|}{ Gender } \\
\hline Male $(n=20)$ & 10 & 6.67 & 2 & 1.33 & 2 & 1.33 \\
\hline Female $(n=130)$ & 80 & 53.33 & 54 & 35.99 & 26 & 17.33 \\
\hline \multicolumn{7}{|l|}{ Marital status } \\
\hline Single $(n=16)$ & 6 & 3.99 & 2 & 1.33 & 0 & 0 \\
\hline Married $(n=130)$ & 80 & 53.33 & 50 & 33.33 & 24 & 15.99 \\
\hline Widow $(n=4)$ & 4 & 2.67 & 4 & 2.67 & 4 & 2.67 \\
\hline \multicolumn{7}{|l|}{ Age group } \\
\hline $21-30(n=10)$ & 2 & 1.33 & 0 & 0 & 0 & 0 \\
\hline $31-40(n=66)$ & 34 & 22.67 & 22 & 14.67 & 8 & 5.33 \\
\hline $41-50(n=60)$ & 44 & 29.33 & 28 & 18.67 & 16 & 10.66 \\
\hline $51-60(n=14)$ & 10 & 6.67 & 6 & 3.99 & 4 & 2.67 \\
\hline
\end{tabular}

Table 3. Distribution of work-related musculoskeletal pain among respondents according to specialties

\begin{tabular}{|c|c|c|c|c|c|c|}
\hline \multirow[t]{2}{*}{ Specialty } & \multicolumn{2}{|c|}{$\begin{array}{c}\text { Have had pain with low back in } \\
\text { the last } 12 \text { months }\end{array}$} & \multicolumn{2}{|c|}{$\begin{array}{l}\text { Have had pain with neck in } \\
\text { the last } 12 \text { months }\end{array}$} & \multicolumn{2}{|c|}{$\begin{array}{l}\text { Have had pain with knee in the } \\
\text { last } 12 \text { months }\end{array}$} \\
\hline & No. & $\%$ & No. & $\%$ & No. & $\%$ \\
\hline$A \& E(n=18)$ & 14 & 77.8 & 14 & 77.8 & 16 & 88.9 \\
\hline Medicine $(n=22)$ & 16 & 72.7 & 16 & 72.7 & 2 & 9.1 \\
\hline Surgery $(n=12)$ & 6 & 50.0 & 6 & 50.0 & 4 & 33.3 \\
\hline ICU $(n=4)$ & 4 & 100 & 4 & 100 & 2 & 50.0 \\
\hline$O \& G(n=16)$ & 6 & 37.5 & 4 & 25.0 & 4 & 25.0 \\
\hline Psychiatry $(n=10)$ & 4 & 40.0 & 4 & 40.0 & 2 & 20.0 \\
\hline Paediatrics $(n=16)$ & 4 & 25.0 & 6 & 37.5 & 4 & 25.0 \\
\hline Children Emergency $(n=12)$ & 6 & 50.0 & 2 & 6.7 & 6 & 50.0 \\
\hline Orthopaedics $(n=8)$ & 6 & 75.0 & 4 & 50.0 & 0 & 0 \\
\hline Theatre $(n=6)$ & 4 & 66.7 & 2 & 33.3 & 2 & 33.3 \\
\hline Dental Dept. $(n=6)$ & 6 & 100 & 0 & 0 & 2 & 33.3 \\
\hline Opthalmology $(n=6)$ & 4 & 66.7 & 0 & 0 & 2 & 33.3 \\
\hline ENT $(n=8)$ & 6 & 75.0 & 6 & 75.0 & 2 & 25.0 \\
\hline Community Health $(n=6)$ & 4 & 66.7 & 4 & 66.7 & 2 & 33.3 \\
\hline Total ( $\mathrm{N}=150)$ & 90 & 60.0 & 72 & 48.0 & 50 & 33.3 \\
\hline
\end{tabular}


from work-related neck pain, while $88.9 \%$ of respondents in Accident and Emergency unit and $50.0 \%$ in Children Emergency suffered from work-related knee pain.

Table 4 shows that LBP caused restriction of any activity in $76(50.7 \%)$ respondents, while $17.3 \%$ of the respondents took some days off because of LBP. Furthermore, $12.0 \%$ of respondents experienced LBP once in a week, $28.0 \%$ once in a month, while $44.0 \%$ experienced LBP more than once in a year. The results also revealed that the main contributing factors related to LBP were frequent bending (64.0\%) followed by prolonged standing (49.3\%) and frequent lifting of patients $(48.0 \%)$. The result on the management of pain showed that $56.0 \%$ of participants preferred having enough rest, $50.7 \%$ preferred using pain killer drugs, $36.0 \%$ preferred exercising exercise, while only $12.0 \%$ had a tendency towards physiotherapy management.

\section{Discussion}

Multiple risk factors such as gender, age, psychosocial profile, work demand and social support have been associated with LBP. Higher rates of LBP have been reported among health workers due to the level of physical and emotional factors involved in their occupation compared with workers in other occupations (24). High incidents of job-related LBP have been reported among nurses due to heavy emotional and physical work, and the exposure to a combination of mechanical and psychosocial stress at work (25).

The one-year prevalence of LBP in this study was $60 \%$. This finding is in line with previous similar studies that reported a high prevalence of work-related musculoskeletal LBP among nurses. Related studies in Nigerian hospitals revealed a high one year prevalence of LBP (71\%) among nurses (26). Lela and Frantz in a study among nurses in Rwanda reported a one-year prevalence of $78 \%$ for LBP (27), similarly, Aljeesh and Al Nawajha reported a prevalence of $70.6 \%$ for LBP among nurses (28). Furthermore, similar studies from Greece and Turkey also reported a high prevalence of LBP among nurses $(29,30)$. This shows that nurses in Nigeria suffer from a high prevalence of LBP as recorded in other countries. Other MSDs reported in this study were neck pain, upper back pain, wrist/hand pain, knee pain and shoulder pain.

Our findings revealed that females (53.33\%) suffered from LBP more than males (6.67\%). This is in accordance with the findings of Sikiru and Hanifa that reported $67.5 \%$ prevalence for LBP among female nurses (31). The reasons for a higher prevalence among female nurses in this study may be related to the higher number of female participants, the anatomical, physiological and structural differences which predispose females to a more mechanical disadvantage (25).

In this study a great proportion of nurses with a high prevalence of LBP were married (53.33\%). This is similar to previous studies that reported a high prevalence for LBP
Table 4. Effects, frequency, aggravating factor and management strategies of low back pain by respondents

\begin{tabular}{|c|c|c|}
\hline & No. & $\%$ \\
\hline \multicolumn{3}{|l|}{ Effect of back pain } \\
\hline It causes restriction of activities & 76 & 50.7 \\
\hline Seeking transfer to another unit & 12 & 8.0 \\
\hline Leaving nursing services & 4 & 2.7 \\
\hline Taking some days off' duty & 26 & 17.3 \\
\hline \multicolumn{3}{|l|}{ Frequency of pain } \\
\hline Daily & 6 & 4.0 \\
\hline Once a week & 18 & 12.0 \\
\hline Once a month & 42 & 28.0 \\
\hline A few times a year & 66 & 44.0 \\
\hline Once a year & 4 & 2.7 \\
\hline \multicolumn{3}{|l|}{ Causative factor } \\
\hline Lifting patient with help (in-bed) & 44 & 29.3 \\
\hline Lifting patient without help (in-bed) & 72 & 48.0 \\
\hline Lifting patient from floor with help & 30 & 20.0 \\
\hline Lifting patient from floor without help & 60 & 40.0 \\
\hline Transferring patient & 48 & 32.0 \\
\hline Bending & 96 & 64.0 \\
\hline Bedside wound dressing & 62 & 41.3 \\
\hline Prolonged standing & 74 & 49.3 \\
\hline Pulling & 42 & 28.0 \\
\hline Twisting & 44 & 29.3 \\
\hline Running during emergency & 36 & 24.0 \\
\hline \multicolumn{3}{|l|}{ How do you manage your pain? } \\
\hline I do not do anything & 30 & 20.0 \\
\hline I take pain killer drugs & 76 & 50.7 \\
\hline I take enough rest & 84 & 56.0 \\
\hline I use back belt/ corset & 14 & 9.3 \\
\hline I reduce movement at work & 50 & 33.3 \\
\hline I reduce movement at home & 58 & 38.7 \\
\hline Use of muscle relaxant & 44 & 29.3 \\
\hline Exercise & 54 & 36.0 \\
\hline Physiotherapy & 18 & 12.0 \\
\hline
\end{tabular}

among married nurses $(27,31)$. In this study, nurses in the age range of 41-50 years demonstrated a higher prevalence of LBP compared to nurses in other age groups. The observed higher prevalence of LBP with ageing agreed with the result from previous studies (26). Ageing is linked with both physiological changes and occupational risk factors. Ageing increases the level of older workers' susceptibility to MSDs (32). Our study revealed that a lower incidence of LBP (6.67\%) was observed among the very senior nurses in the age group of 51-60. The lower incidence observed in this study may be attributed to the involvement in more administrative duties, less patient handling, acquisition of adequate knowledge about injury prevention and proper patient lifting techniques over the years (33).

In the present study, ICU, Dental, A\&E and Orthopedics reported the highest incidence of LBP with $100 \%, 100 \%$, 
$77.8 \%$ and $75.0 \%$, respectively, while Pediatrics (25.0\%) and Obstetrics and Gynaecologic (37.5\%) reported the least. This result is in line with the study conducted by Abou El-Soud et al that reported $95.0 \%$ prevalence of LBP among nurses working in the ICU (34). The high prevalence of LBP in these departments may be attributed to the unique time constraint in responding to emergency situations, nature of the work that demands prolonged standing and heavy workloads.

Bending (64\%) and prolonged standing (49.3\%) were reported by the respondents as the main risk factors responsible for LBP in this study. Other patient care activities that contributed to LBP were Lifting patient from floor without help (48\%), patients' wound dressing (41.3\%), lifting patient from floor without help (40\%), and transferring patients (32.0\%). This is similar to the studies done by Wong et al and Abou El-Soud et al, that reported bending forward (69.8\%), prolonged standing (73.9\%), twisting, prolonged sitting, and walking for long distances as different work postures that predispose nurses to an increased risk of back pain $(34,35)$. This study showed that LBP causes restriction of activities in majority of the respondents. This is in line with reports from previous studies that work-related LBP has a negative effect on functional independence and working ability in working population $(36,37)$.

Involvement of physiotherapy as a management strategy for LBP is yet to be fully appreciated in this research environment as majority of the respondents reported that they preferred to manage their LBP by taking enough rest (56\%), while only $12.0 \%$ reported the need for physiotherapy. This is similar to a study report by Cilliers et al, where $51.0 \%$ of the participants preferred bed rest after developing LBP to other treatments (38).

\section{Conclusion}

Work-related MSDs are often reported by Nigerian nurses. Work-related LBP appears to be the most common MSD affecting females more than males. Intensive Care Unit, Dental, Accident and Emergency and Orthopedics are the specialties with the highest incidence of work-related LBP. Frequent bending, prolong standing, lifting patients in the bed without assistance, and bedside wound dressing were the most reported work-related risk factors for LBP. Restriction of activities and taking days off duty are the major consequences of LBP. Management of LBP with physiotherapy has not been fully established among nurses as few of the nurses attended physiotherapy during their episodes of back pain. We recommend educational back care programs, back care ergonomics and patient transfer should be organised for nurses in order to reduce the rate of work-related MSDs. In addition, adequate transferring or lifting equipment should be procured and be available in hospitals in order to reduce the high prevalence of LBP among nurses.

\section{Ethical issues}

The study protocol was approved by the Health Research Ethics Committee of Federal Medical Centre, Owo (FMC/ OW/380/LXV111/67).

\section{Authors' contributions}

SOB conceived the idea for this study, participated in the design of methodology and data collection and prepared the final manuscript for publication. IO participated in the design of methodology and data collection and drafted the manuscript. AFA conducted the analysis and interpretation of data and drafted the manuscript. All authors read and approved the final manuscript.

\section{References}

1. Punnett L, Wegman DH. Work-related musculoskeletal disorders: the epidemiologic evidence and the debate. J Electromyogr Kinesiol 2004; 14(1): 13-23. doi: 10.1016/j. jelekin.2003.09.015.

2. Smith DR, Leggat PA. Musculoskeletal disorders in nursing. Aust Nurs J 2003; 11(1): 19-21.

3. Gopal K, Thomas M, Sreedharan J. Work-related musculoskeletal disorders (WMSD) in hospital nurses: Prevalence and coping strategies. Gulf Medical Journal 2012;1(S1):S159-63.

4. Salik Y, Ozcan A. Work-related musculoskeletal disorders: a survey of physical therapists in Izmir-Turkey. BMC Musculoskelet Disord 2004; 5: 27. doi: 10.1186/1471-24745-27.

5. Arvidsson I, Gremark Simonsen J, Dahlqvist C, Axmon A, Karlson B, Bjork J, et al. Cross-sectional associations between occupational factors and musculoskeletal pain in women teachers, nurses and sonographers. BMC Musculoskelet Disord 2016; 17: 35. doi: 10.1186/s12891016-0883-4.

6. Menzel NN, Brooks SM, Bernard TE, Nelson A. The physical workload of nursing personnel: association with musculoskeletal discomfort. Int J Nurs Stud 2004; 41(8): 859-67. doi: 10.1016/j.ijnurstu.2004.03.012.

7. Josephson M, Lagerstrom M, Hagberg M, Wigaeus Hjelm E. Musculoskeletal symptoms and job strain among nursing personnel: a study over a three year period. Occup Environ Med 1997; 54(9): 681-5. doi: 10.1136/oem.54.9.681.

8. Smedley J, Egger P, Cooper C, Coggon D. Manual handling activities and risk of low back pain in nurses. Occup Environ Med 1995; 52(3): 160-3. doi: 10.1136/oem.52.3.160.

9. Yip Y. A study of work stress, patient handling activities and the risk of low back pain among nurses in Hong Kong. J Adv Nurs 2001; 36(6): 794-804.

10. Smith DR, Leggat PA, Smyth W, Wang RS. Musculoskeletal disorders among female Australian nurses working in a unique tropical environment: results from a pilot study. Ergon Aust 2003; 17 (3): 14-7.

11. Lagerstrom $M$, Wenemark $M$, Hagberg $M$, Hjelm EW. Occupational and individual factors related to musculoskeletal symptoms in five body regions among Swedish nursing personnel. Int Arch Occup Environ Health 1995; 68(1): 27-35.

12. Bongers PM, Kremer AM, ter Laak J. Are psychosocial 
factors, risk factors for symptoms and signs of the shoulder, elbow, or hand/wrist?: A review of the epidemiological literature. Am J Ind Med 2002; 41(5): 315-42. doi: 10.1002/ ajim. 10050 .

13. Smith DR, Wei N, Zhao L, Wang RS. Musculoskeletal complaints and psychosocial risk factors among Chinese hospital nurses.Occup Med (Lond) 2004; 54(8): 579-82. doi: 10.1093/occmed/kqh117.

14. Holder NL, Clark HA, DiBlasio JM, Hughes CL, Scherpf JW, Harding L, et al. Cause, prevalence, and response to occupational musculoskeletal injuries reported by physical therapists and physical therapist assistants. Phys Ther 1999; 79(7): 642-52. doi: 10.1093/ptj/79.7.642.

15. Badley EM, Rasooly I, Webster GK. Relative importance of musculoskeletal disorders as a cause of chronic health problems, disability, and health care utilization: findings from the 1990 Ontario Health Survey. J Rheumatol 1994; 21(3): 505-14.

16. Riihimaki H. Hands up or back to work--future challenges in epidemiologic research on musculoskeletal diseases. Scand J Work Environ Health 1995; 21(6): 401-3.

17. Kemmlert K. Prevention of occupational musculo-skeletal injuries. Labour Inspectorate investigation. Scand J Rehabil Med Suppl 1996; 35: 1-34.

18. Ando S, Ono Y, Shimaoka M, Hiruta S, Hattori Y, Hori F, et al. Associations of self estimated workloads with musculoskeletal symptoms among hospital nurses. Occup Environ Med 2000; 57(3): 211-6. doi: 10.1136/oem.57.3.211.

19. Kim YO, Koo JW. Musculoskeletal symptoms and related factors on the nurses in several general hospitals'. Korean J Occup Health Nurs 2002; 41(3): 131-41.

20. Daynard D, Yassi A, Cooper JE, Tate R, Norman R, Wells R. Biomechanical analysis of peak and cumulative spinal loads during simulated patient-handling activities: a substudy of a randomized controlled trial to prevent lift and transfer injury of health care workers. Appl Ergon 2001; 32(3): 199214.

21. Wilkinson WE, Salazar MK, Uhl JE, Koepsell TD, DeRoos RL, Long RJ. Occupational injuries: a study of health care workers at a northwestern health science center and teaching hospital. AAOHN J 1992; 40(6): 287-93.

22. Harber P, Billet E, Gutowski M, SooHoo K, Lew M, Roman A. Occupational low-back pain in hospital nurses. J Occup Med 1985; 27(7): 518-24.

23. Kuorinka I, Jonsson B, Kilbom A, Vinterberg H, BieringSorensen F, Andersson G, et al. Standardised Nordic questionnaires for the analysis of musculoskeletal symptoms. Appl Ergon 1987; 18(3): 233-7.

24. Al-samawi MAG, Abdallah Awad HAM. Why do women have back pain more than men? A representative prevalence study in the federal republic of Germany. Clin J Pain 2006; 22(8): 738-47. doi: 10.1097/01.ajp.0000210920.03289.93.
25. Al-samawi MAG, Abdallah Awad HAM. Prevalence of low back pain among nurses working In Elmak Nimer university hospital. International Journal of Research Granthaalayah 2015; 3(9): 108-21.

26. Sikiru L, Shmaila H. Prevalence and risk factors of low back pain among nurses in Africa: Nigerian and Ethiopian specialized hospitals survey study. East Afr J Public Health 2009; 6(1): 22-5.

27. Lela M, Frantz JM. Physical activity among nurses in Kanombe military hospital. African Journal of Physiotherapy and Rehabilitation Sciences 2012; 4(1-2): 63-6. doi: 10.4314/ajprs.v4i1-2.10.

28. Aljeesh Y, Al Nawajha S. Determinants of low back pain among operating room nurses in Gaza governmental hospitals. J Al Azhar Univ (Nat Sci) 2011; 13: 41-54.

29. Roupa Z, Vassilopoulos A, Sotiropoulou P, Makrinika E, Noula M, Faros E, et al. The problem of lower back pain in nursing staff and its effect on human activity. Health Sci J 2008; 2(4): 219-25.

30. Karahan A, Kav S, Abbasoglu A, Dogan N. Low back pain: prevalence and associated risk factors among hospital staff. J Adv Nurs 2009; 65(3): 516-24. doi: 10.1111/j.13652648.2008.04905.x.

31. Sikiru L, Hanifa S. Prevalence and risk factors of low back pain among nurses in a typical Nigerian hospital. Afr Health Sci 2010; 10(1): 26-30.

32. Bejia I, Younes M, Jamila HB, Khalfallah T, Ben Salem K, Touzi M, et al. Prevalence and factors associated to low back pain among hospital staff. Joint Bone Spine 2005; 72(3): 254-9. doi: 10.1016/j.jbspin.2004.06.001.

33. Charlotte ER, Stuart GP. Molecular genetics and age-related disease. Age Ageing 2001; 30: 449-54.

34. Abou El-Soud AM, El-Najjar AR, El-Fattah NA, Hassan AA. Prevalence of low back pain in working nurses in Zagazig University Hospitals: an epidemiological study. Egyptian Rheumatology and Rehabilitation 2014; 41(3): 109-15. doi: 10.4103/1110-161x.140525.

35. Wong TW, Teo N, Kyaw MO. Prevalence and risk factors associated with low back among health care providers in a District Hospital. Malays Orthop J 2010; 4(2): 23-8.

36. Reid MC, Williams CS, Gill TM. Back pain and decline in lower extremity physical function among communitydwelling older persons. J Gerontol A Biol Sci Med Sci 2005; 60(6): 793-7. doi: 10.1093/gerona/60.6.793

37. Leveille SG, Zhang Y, McMullen W, Kelly-Hayes M, Felson DT. Sex differences in musculoskeletal pain in older adults. Pain 2005; 116(3): 332-8. doi: 10.1016/j.pain.2005.05.002.

38. Cilliers L, Maart S. Attitudes, knowledge and treatment of low back pain amongst nurses in the Eastern Cape, South Africa. Afr J Prim Health Care Fam Med 2013; 5(1): 535. doi: 10.4102/phcfm.v5i1.535. 